\title{
ORIGINALES
}

\section{Comportamiento sexual bajo la influencia del alcohol en adolescentes españoles}

\section{Sexual behaviour under the influence of alcohol among Spanish adolescents}

José P. Espada; Alexandra Morales; Mireia

Orgilés;José A. Piqueras; José L. Carballo

| Miguel Hernández University

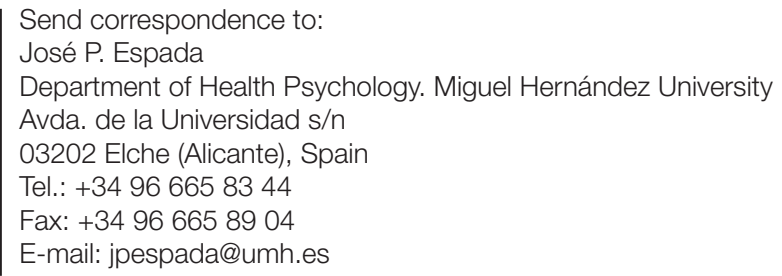

\section{Resumen}

Este trabajo tiene como objetivo comparar el comportamiento sexual y los factores protectores y de riesgo entre adolescentes que mantienen relaciones sexuales bajo la influencia del alcohol y los que no lo hacen, y determinar los factores predictores de la combinación sexo y drogas. Se analizaron las diferencias entre estos dos grupos en comportamiento sexual, actitud hacia el VIH, norma subjetiva y conocimientos sobre el VIH. Mediante medidas de autoinforme fueron evaluados 1216 adolescentes españoles entre 14 y 18 años ( $M=15.92$, DT = .76), fueron seleccionados 297 por ser sexualmente activos. De estos, 117 informaron haber mantenido relaciones sexuales bajo la influencia del alcohol en los últimos seis meses (51\% fueron chicas). Los adolescentes que combinaron sexo y alcohol se implicaron en mayor medida en sexo vaginal, sexo oral y sexo anal respecto a los que no lo hicieron. Haber mantenido relaciones sexuales bajo la influencia del alcohol en los últimos seis meses se relacionó con una actitud negativa hacia el uso del condón cuando existen obstáculos para su uso y menor uso consistente del preservativo. No hubo diferencias en el conocimiento sobre el VIH entre ambos grupos. Los adolescentes que combinaron sexo y alcohol presentaron en mayor medida caracteristicas asociadas con el riesgo sexual. Las medidas preventivas deben atender a las características particulares de este grupo de riesgo. Se requiere mayor evidencia de los efectos del alcohol sobre el comportamiento sexual.
Palabras clave: Consumo de alcohol, conducta sexual, VIH, uso consistente preservativo, adolescencia.

\section{Abstract}

This paper aims to compare sexual behaviour and risk and protective factors between samples of adolescents who have sex under the influence of alcohol and those who do not, and to determine predictors factors for having had sex under the influence of alcohol. We analysed differences between these two groups in sexual practices, attitudes towards HIV, subjective norms and HIV knowledge. Drawing on survey data collected from 1216 Spanish adolescents aged 14-18 ( $M=15.92 ; S D=.76)$, a subset of 297 sexually experienced participants was selected. Of these, 117 reported having had sex under the influence of alcohol in the past six months ( $51 \%$ girls). Adolescents who combined sex and alcohol engaged more in vaginal sex, oral sex and anal sex than those who did not. Having had sex under the influence of alcohol in the past six months was associated with negative attitudes towards condom use, when there are obstacles on using them, and less consistent condom use. There were no differences in knowledge about STIs/HIV between both groups. Adolescents who combined sex and alcohol showed further characteristics associated with sexual risk. Preventive measures must address the particular characteristics of this risk group. Further evidence is need about alcohol effects on sexual behaviour.

Key Words: Alcohol use, sexual behaviour, HIV, consistent condom use, adolescence. 
l: is estimated that 2500 young people in the world become infected everyday with the HIV (UNICEF, 2011). In 2010, $12 \%$ of the 118.335 new HIV infections diagnosed in Europe were in 15-24-year-old individuals. Spain has one of the highest prevalence rates among the European Union countries with a rate of 2.0 per 100.000 population (930 cases) in 2010 (European Centre for Disease Prevention and Control/ WHO Regional Office for Europe, 2011; Spanish Department of Health, Social Policy and Equality, 2011). Of the total reported cases of VIH in 2009, 26.4\% were under the age of 29 years. One of the main factors associated with sexual risk is alcohol use (WHO, 2005). Alcohol is the most consumed drug in order to facilitate the sexual encounter and increase sexual arousal in youth (Bellis et al., 2008; Calafat, Juan, Becoña, \& Mantecón, 2008). It is known that alcohol consumption may reduce the perception of risk, increase feelings of invulnerability (Antón \& Espada, 2009) and reduce ability to negotiate safe sex (Bauermeister, Zimmerman, Caldwell, Xue, \& Gee, 2010). However the relationship between alcohol and sexual risk is not simple, and there are many factors underlying the relationship between alcohol or drug use and sexual risk taking behaviour (Cooper, 2006). Personal characteristics and specific contextual factors have a moderating effect between drug use and sexual risk.

Despite efforts to understand how alcohol affects sexual behavior, data are not consistent across samples and settings (García et al., 2006; Leigh \& Stall, 1993). Alcohol use and sexual risk behaviours tend to co-occur in recreational nightlife settings in youth (Bellis et al., 2008; Calafat, Juan, Becoña, Mantecón, \& Ramón, 2009; Lomba, Apóstolo, \& Mendes, 2009). It is estimated that $50 \%$ of young people have combined sex and drugs at least once in their lives (Antón \& Espada, 2009; Lomba et al., 2009). Some studies indicate that having had sex under alcohol use increases the likelihood of exposure to sexually transmitted infections (Antón \& Espada, 2009; Goldstein, Barnett, Pedlow, \& Murphy, 2007; Leigh \& Stall, 1993; Seth et al., 2011; Weinhardt \& Carey, 2000) and this effect is independent of gender (Becoña, Juan, Calafat, \& Ros, 2008). Consistent condom use is a highly effective HIV/ STIs prevention strategy. In this regard, Sarkar (2008) found that alcohol consumption is a barrier to condom use. Almost half of young people felt that alcohol and other drugs influence them to have unsafe sex (Lomba et al., 2009). In a review, Cooper (2002) concluded that alcohol may affect the decision to engage in risky sex. Also, alcohol has been shown to be related to sexual risk indicators like early sexual onset (Bellis et al., 2008; Lomba et al., 2009) and the number of sexual partners (Cooper, 2002; Dogan, Stockdale, Widaman, \& Conger, 2010; Lomba et al., 2009; Seth et al., 2011). According to these studies, youth who consume alcohol tend to report an earlier sexual onset and greater number of sexual partners compared to those do not.

On the other hand, other studies have not found a clear association between alcohol use and sexual risk behaviours (Graves, 1995; Morrison et al., 2003; Pollock et al., 2012). There exists some evidence to suggest that adolescents who use condoms regularly continue to do so under the influence of alcohol (Weinhardt \& Carey, 2000). A cross-sectional study of 7441 young people demonstrated that substance use at last sexual intercourse was not associated with the likelihood of using a condom at last coitus (Santelli, Robin, Brener, \& Lowry, 2001). Studies that have measured daily activity for periods of time have not found that alcohol use is related to an increase of sexual risk, such as Leigh (1993). Pre-existing individual beliefs about alcohol's influence on behaviour have been shown to have an important effect on behaviour (Cooper, 2006; Patrick \& Maggs, 2009). According to Hull and Bond (1986), similar behaviour is observed among people who believe they have consumed alcohol (but had not) and those who have consumed alcohol (but did not know it). Other "third variables" may mediate the relationship between alcohol use and sexual behaviour such as sexual sensation seeking and a lifestyle based on risk (Zuckerman, 2007). However, longitudinal studies such as Dogan et al. (2010) conclude that alcohol use is an indicator of change in sexual behaviour throughout adolescence. This effect remains despite the potential influence of "third variables" such as impulsivity and excitement seeking.

In addition to the consumption of alcohol, cognitive and attitudinal factors have been shown to be related to risky sexual behaviour. According to the Theory of Planned Action (Ajzen, 1991), individual's knowledge and attitudes related to performing the behaviour and perceived social norms about the behaviour are significant predictors of behaviour. Given that alcohol may be associated with risky sexual behaviour, it is possible that there is some relationship between sex after consuming alcohol in the past six months and predictors of sexual behaviour, such as HIV knowledge, attitude towards HIV and subjective norms.

In light of the importance of the issue and the lack of consensus on the results, more research is needed to analyze the relationship between having sex under the influence of alcohol and sexual risk. Many of the reviewed studies evaluated this relationship but do not take into account cognitive predictors of sexual risk (Ajzen, 1991). The main aim of this study is to compare sexual risk behaviour and cognitive factors (HIV Knowledge, attitude towards HIV and condom and subjective norm) between adolescents who use alcohol prior to sex and those who do not, among a Spanish adolescent sample. The second goal is to identify predictors of having had sex under the influence of alcohol in the past six months in order to construct a predictive model.

\section{Method}

\section{Participants}

This study is part of a cross-sectional survey carried out in Spain, in which 1216 adolescents between ages 14 and 18 years participated $(M=15.92 ; S D=.76)$, of whom $96(7.89 \%)$ were excluded from the analyses because of errors or omissions in their responses. From this sample, we selected adolescents who reported being sexually active during the last six 
months ( $n=297)$. Of these, there were 57 boys and 60 girls ( $n$ $=117 ; 39.4 \%)$, with a mean age of 16.15 ( $S D=.83$; range 15 18), reported having had sex under the influence of alcohol in the past six months. The other 180 adolescents (of whom 107 [59.4\%] were girls), with a mean age of 15.74 (SD $=.70$; range 15 - 18), reported not mixing sex and alcohol in the past six months.

\section{Measures}

Sexual behaviours were assessed according to conventional procedures (Bersamin et al., 2009). To be selected for the study, participants were asked whether they had ever had a sexual intercourse. For sexually active adolescents, the following information was requested: a) alcohol use prior to sex in the past six months (Have you ever had sex under the influence of alcohol in the past six months?), with dichotomous response; b) age at first sexual intercourse; c) type of sexual relationship in the past six months; d) number of partners in the past six months; e) condom use at first intercourse (dichotomous variable); f) rate of condom use in their sexual relationships ( $0 \%$ to $100 \%)$, and g) perception of peers' condom use (dichotomous variable).

In order to assess HIV knowledge we used the HIV Knowledge Scale for Spanish Adolescents (HIV-KS; Espada et al., 2009), which consists of 10 items and produces a total score that ranges from 0 to 10 , with higher scores indicating greater knowledge. It is composed of 3 factors: a) beliefs about oral transmission of HIV; b) knowledge of the impact of HIV; and c) knowledge about other routes of HIV transmission. Internal consistency of the scale was.76.

Students also completed the HIV Attitudes Scale for Adolescents (HIV-AS; Espada et al., 2013). The instrument was composed of 12 4-point ranged items grouped into four subscales: a) Attitudes towards safe sex when there is an obstacle to condom use; b) Attitudes towards HIV testing; c) Attitudes towards condom use; d) Attitudes towards HIV-positive people. The questionnaire yielded an internal consistency of .77.

It was evaluated the peer condom use perception using percentage estimations of adolescents who perceive that their peers use condom in their sexual intercourse.

\section{Procedure}

Fifteen secondary schools randomly selected from five Spanish provinces, all located in urban areas, participated in this study: three from the north of the country, two from the south, three from the east, four from the southeast, and three from the centre. Only 5\% of the schools that were approached could not partake in the study because of conflicts with other activities. After approval of the study by the ethics committee of the Miguel Hernandez University, permission from the institutions and informed consent by the participants and their parents were sought. The assessment took one hour and teachers were not present in the classroom in order to maintain confidentiality and facilitate honest survey responses by students. Students did not receive any incentives for participating.

\section{Statistical Analyses}

All analyses were conducted using SPSS 19. We used chisquare analyses for categorical variables and $t$-tests for continuous variables to test the study hypotheses. Effect sizes were calculated using odds ratio $(O R)$ and $d$ Cohen index, where values lower or equal to 20 are considered very small effect size; values between .21 and .49 small one; medium to values between .50 and .79; and values equal or higher than .80, a large effect (Cohen, 1988).

Logistic regression analyses were carried out to assess the predictive value of risk variables on having had sex under the influence of alcohol in the past six months coded as 1 and non-having had sex under the influence of alcohol as 0 , in a sample of sexually active adolescents.

\section{Results}

\section{Cognitive Factors and Sexual Behaviour}

Table 1 shows the results for comparisons in sexual risk factors between adolescents who had sex under the influence of alcohol and those who did not in the past six months; attending for gender differences. Our results indicate that knowledge about HIV was not associated with having had sex after consuming alcohol in the past six months. Although gender differences were found in the group of adolescents who had not consumed alcohol; boys scored higher on knowledge related to impact of HIV than girls of the same group ( $p$ $=.001)$. According to Cohen (1988), the effect size for this comparison was very high $(d=.96)$.

Having had sex under the influence of alcohol in the past six months was related to the attitude toward condom use when there are obstacles to using them. Compared to adolescents who had sex under the influence of alcohol in the past six months, those who did not reported significantly more favourable attitude toward condom use when barriers exist to use it $(p=.001)$, especially girls. However, this gender difference was only significant in the group of adolescents who did not have sex after alcohol consumption $(p=.005)$. Among adolescents who had sex under alcohol influence in the past six months, girls reported more positive attitude towards those infected by HIV/AIDS respect to boys $(p=.021)$. Having had sex under alcohol influence in the past six months was not related to the attitude toward HIV infection, but it did to the gender. In both groups, girls showed more positive attitudes toward HIV infection when compared to boys of the same group. The magnitudes of the differences found were between .25 and .48 , range that indicates a low effect size on the attitudinal level.

Perception of their peers' condom use was high and it was not related to having had sex under the influence of alcohol in the past six months $(p=.201)$. However, gender differences were found in the group of participants that did not have sex under the influence of alcohol. The probability of perceiving that peers use condoms in 
their relationships was three times greater in girls than boys of the same group $(p=.047, O R=3.03, C l=2.94-3.12)$.

Data on sexual behaviour revealed that having had sex under the influence of alcohol in the past six months was not related to age at first intercourse $(p=.112)$ or number of sexual partners in the past six months ( $p=.057)$; but it was to sexual practices and consistent condom use. ORs point out those adolescents who had sex after consuming alcohol in the past six months involved in more sexual practices compared to those who did not. Such increase was 4.12 times for vaginal $\operatorname{sex}(p=.001), 2.65$ for oral $\operatorname{sex}(p=.001)$ and 2.92 for anal $\operatorname{sex}(p=.016)$. Furthermore, gender differences were observed in sexual practices in the past six months among adolescents who had no sex under the influence of alcohol. In this group, having had vaginal sex in the past six months was 2.56 times less likely among boys than girls $(p=.003)$. However, the probability of having had mutual masturbation $(p=.001, O R=$ 3.73, $\mathrm{Cl}=3.67-3.79)$ and anal $\operatorname{sex}(p=.042, O R=4.51, \mathrm{Cl}=$ 4.51-4.90) was higher in boys than girls. Low consistent condom use rate was found among participants. Despite of this, having used condoms consistently was 1.40 times less likely among youths who had sex under the influence of alcohol in the past six months in comparison to those who had not (44.1\% vs. $64.1 \%)(p=.002, O R=.71, C l=.70-.72)$.

\section{Predictive value of risk variables on having sex under the influence of alcohol}

A binary logistic regression analysis was conducted to identify predictors of having had sex under the influence of alcohol in the past six months. From a theoretical point of view, independent variables included were those considered potential predictors for risky sex: knowledge about HIV, attitude towards HIV, attitude toward an obstacle to condom use and perception that their peers use condom. The model created to predict having had sex under the influence of alcohol in the past six months allowed the correct estimation of $68.4 \%$ of the cases $\left(\chi^{2}=28.06, p<.001\right)$ with all variables forming part of the equation. The fit value obtained ( $R^{2}$ Nagelkerke) was 12 .

As shown in Table 2, attitude towards condom use when there are obstacles to using them $(O R=.68 ; 95 \% \mathrm{Cl}=.56-.81)$ had an independent effect when statistically predicting having had sex under alcohol influence in the past six months. The model indicates that high scores in attitude towards condom use when there are obstacles to using them is a protective factor for having had sex under the influence of alcohol in the past six months. The knowledge about HIV, attitude towards HIV and perception related to peers' condom use were not related to having had sex under the influence of alcohol in the past six months.

\section{Discussion}

Although it is generally accepted that alcohol consumption increases risky sexual behaviour, some studies do not sup- port this assertion. The current study identifies what specific aspects of sexual activity, cognitive and attitudinal factors are related to having had sex after consuming alcohol in the past six months among sexually active adolescents. Our results contribute to a better understanding of sexual and cognitive profile of adolescents who have sex under the influence of alcohol. Data revealed different sexual risk profile between those who had had sex after consuming alcohol and those had not in the past six months, in terms of sexual practices, attitude toward condom use when there are obstacles to using them and consistent condom use.

The results showed that $40 \%$ of sexually active adolescents had sex under the influence of alcohol in the past six months. Although the rate is relatively high, it is slightly lower than other studies using young adult samples (Antón \& Espada, 2009; Lomba et al., 2009), indicating that rate of adolescents who have sex under the influence of alcohol use may increase as they transition into young adulthood. In this study, having had oral, vaginal and anal sex in the past six months increased the probability of having had sex under the influence of alcohol in 4.12, 2.65 and 2.92 times respectively, in comparison to those did not engage in these practices. The effect size of these comparisons indicated that adolescents who had sex under the influence of alcohol in the past six months were more than twice more likely to having engaged in these practices than their partners who had not. Hence alcohol could be considered a sexual encounter facilitate, at least in this sample of sexuaIly active adolescents. In this sense, Vélez-Blasini (2008) also observed college students reported using alcohol engage in coital sexual relations more frequently. Alcohol has been linked to an early sexual onset (Bellis et al., 2008; WHO, 2005). However, no significant difference in the age of sexual initiation between the two groups was found. In this study, alcohol was not a facilitator for sexual encounters with new partners, unlike prior studies as Costa, Jessor, Donovan, \& Fortenberry (1995). Our result could be explained by the short period of time the participants were sexually active. Other studies found a greater number of sexual partners in consumers of alcohol and other drugs (Bellis et al., 2008; Cooper, 2002; Dogan et al., 2010), although many of them used samples of young adults.

Regarding cognitive factors, having had sex under the influence of alcohol in the past six months was only variable related to attitude towards HIV when there obstacles to use them. Despite being equally informed and having similar peer norms related to condom use, adolescents who had no sex under the influence of alcohol in the past six months showed more favourable attitudes toward condom use, especially when it is difficult to access. Although effect size was low (Cohen, 1988), it does not imply this difference is not relevant; a low effect size may indicate that the relevance of a real difference could not be supported empirically (Sohn, 1982). In Spain, one of the main reasons reported by youths for not using condoms consistently were the difficulties involved with acquiring them at the time of sexual relations (Calafat et al., 2009; Rodríguez, Hernán, Cabrera, García, \& Romo, 2007). The regression analysis pointed out that a favourable attitude toward condom use when there are obstacles is a protective factor for having had sex under the influence of alcohol. Therefore, facilitation of 
Table 1. Sexual risk factors and sex under the influence of alcohol in the past six months $(n=297)$ Sex under the influence of alcohol ( 57 boys and 60 girls) / Sex without the influence of alcohol (73 boys and 107 girls)

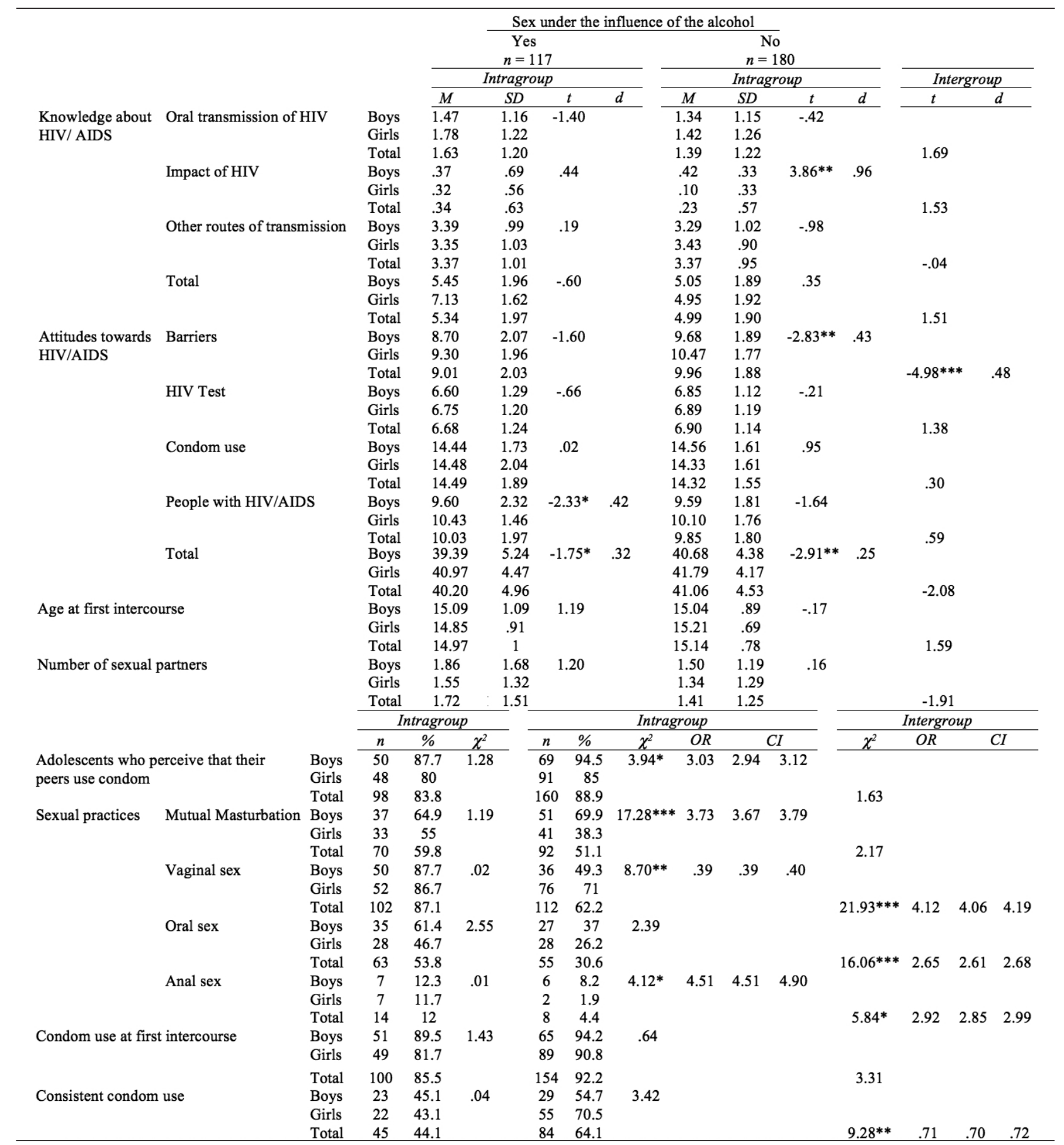

Note. $C l=$ confidence interval; $d=$ Cohen effect size; $O R=$ Odds Ratio; ${ }^{*} p<.05^{* *} p<.01{ }^{* * *} p<.001$.

Table 2. Predictive value of risk variables on having sex under the influence of alcohol in the past six months $(n=297)$

\begin{tabular}{|c|c|c|c|c|c|c|c|}
\hline \multirow[b]{2}{*}{ Predictors } & \multirow[b]{2}{*}{ B } & \multirow[b]{2}{*}{ SE } & \multirow[b]{2}{*}{$\begin{array}{c}\text { Wald } \\
\text { Statistic }\end{array}$} & \multirow[b]{2}{*}{$p$} & \multirow[b]{2}{*}{$\mathrm{OR}$} & \multicolumn{2}{|c|}{$95 \% \mathrm{Cl}$} \\
\hline & & & & & & Lower & Upper \\
\hline Knowledge about HIV & .07 & .06 & 1.15 & .28 & 1.07 & .94 & 1.23 \\
\hline Attitude towards HIV & .05 & .03 & 1.96 & .16 & 1.05 & .97 & 1.14 \\
\hline Attitude towards an obstacle to condom use & -.38 & .09 & 17.31 & $.00^{* * *}$ & .68 & .56 & .81 \\
\hline Perception related to peers's condom use & -.14 & .36 & .14 & .70 & .86 & .42 & 1.78 \\
\hline
\end{tabular}

Note. $B=$ regression coefficient, $S E=$ standard error, $O R=$ odds ratio, $C l=$ confidence interval; $\chi^{2}=28.06$; Classification table: Sex under the influence of alcohol $(n=117) /$ Sex without the influence of alcohol $(n=180) ; R^{2}=.12 ; * * * 0.001$ 
access to condoms could be a useful strategy for prevention of HIV and unwanted pregnancies, especially among adolescents who have sex under the influence of alcohol.

According to the Theory of Planned Action (Ajzen, 1991), more favourable attitude towards condom use increases the probability of using condoms consistently in sexual relationship. In this study, adolescents who had no sex under the influence of alcohol, besides showing more favourable attitude towards condom use, they reported more consistently condom use in comparison to those who had sex after consuming alcohol. This finding provides empirical evidence of the impact of attitude on behavior; however a causal attribution is not possible due to the analyses used. Participants who having had sex under alcohol influence in the past six months reported less consistent condom use than those who had not. This result is consistent with previous studies (Pingel et al., 2012; Sarkar, 2008). Other factors may mediate the relationship between alcohol use and sexual risk such as personality traits (Leigh \& Stall, 1993; Moilanen, Crockett, Raffali, \& Jones, 2010) and motivations to engage in alcohol use and sexual intercourse (Calafat et al., 2008; Patrick et al., 2010). Future research including these factors would be beneficial to understand better the effect alcohol on sexual behavior.

Gender determined much of sexual behaviour and cognitive variables observed in adolescents who reported not having had sex under the influence of alcohol in the past six months. The relevance of these gender differences was supported empirically though high effect size in informational variables and low effect size for attitudinal ones. While boys engaged more in this behavior than girls among samples recruited in recreational contexts (Calafat et al., 2009), there were no gender differences in high school students. In the group who had sex after consuming alcohol in the past six months, the pattern of sexual behaviour and scores on the predictors of behaviour were similar between boys and girls. This result suggests that sexual risk assumed does not differ between the sexes when adolescents have sex under the influence of alcohol. Overall, girls had more favourable attitudes towards those affected by the virus and to HIV infection, suggesting that they are more aware with the HIV epidemic. Calafat et al. (2009) also found higher perception of risk among women, but paradoxically, they were involved more in risky sexual behaviour compared with males. Gender differences in sexual risk factors may be explained by social-cultural norms, as expectations of specific behaviors for men and women differ based on conservative gender roles (Espada, Orgilés, Morales, Ballester, \& HuedoMedina, 2012). In this study, respect to boys, girls reported more favourable attitudes towards condom use when there are difficulties in acquiring them but there were no gender differences in the consistent use of condoms. According to this result, we can expect women to use condoms to a greater extent when there are difficulties in acquiring them respect to boys. Another possible explanation is that attitude does not always predict behaviour as it has been found in previous studies (Godin et al., 1996). It requires more empirical evidence on this issue.

It is important to consider methodological limitations that may have had an effect on the results. By using a cross-sectio- nal design, we cannot establish causal relationships between alcohol consumption and risky sexual behaviours. It requires more evidence of the influence of alcohol on sexual behaviour using prospective designs. The generalizability of the current findings may be limited to a small sample of sexually active adolescents. Future research should replicate this study with a larger sample size and controlling "third variables" like preexisting beliefs about alcohol's effect on behaviour. Outcomes were measured with self-reports, which can be influenced by socially desirable responding. The desirability effect was minimized by administrating the questionnaires to small groups and assigning personal codes.

The present study also had important strengths. Few studies on Spanish teenagers have so far addressed the issue of alcohol consumption in combination with sexual intercourse outside the context recreational. Ours provides further evidence on the relationship between alcohol intake and sexual risk behaviour in adolescents, identifies what specific aspects of sexual activity differ, and determines the predictors for risky sex. Many sex education and HIV prevention programmes only focus on informing about pregnancy, STIs, prevention methods and improving attitudes towards condom use. This focus is insufficient: in order to prevent risky sexual behaviour. It is essential that this group's characteristics be taken into account, namely, their attitude to condom use when there are obstacles to using them, consistent condom use and reasons for drinking alcohol. Adolescence is a critical period to risk assumption and further evidence is needed between alcohol consumption and sexual behaviours in this population.

\section{Acknowledgements}

This study was supported by the Spanish Foundation for AIDS Investigation and Prevention (FIPSE; grant number 360971/10).

\section{Declaration of interest}

The authors report no conflicts of interest.

\section{References}

Ajzen, I. (1991). The Theory of Planned Behavior. Organizational Behavior and Human Decision Processes, 50, 179-211. doi:10.1016/07495978(91)90020-T

Antón, F. A. \& Espada, J. P. (2009). Consumo de sustancias y conductas sexuales de riesgo para la transmisión del VIH en una muestra de estudiantes universitarios. Anales de Psicología, 25, 344-350. doi: 02126559 
Bauermeister, J. A., Zimmerman, M. A., Caldwell, C., Xue, Y., \& Gee, G. C. (2010). What predicts sex partner age differences among African American youth? A longitudinal study from adolescence to young adulthood. The Journal of Sex Research, 47, 330-344. doi: $10.1080 / 00224490903015850$

Becoña, E., Juan, M., Calafat, A., \& Ros, M. (2008). Razones para no aceptar una relación sexual en jóvenes que se divierten en contextos recreativos nocturnos en función del género y la embriaguez. Adicciones, 20, 357-364.

Bellis, M. A., Hughes, K., Calafat, A., Juan, M., Ramon, A., Rodríguez, J. A.,... Phillips-Howards, P. (2008). Sexual uses of alcohol and drugs and the associated health risks: A cross sectional study of young people in nine European cities. BMC Public Health, 8, 155. doi: 10.1186/1471-2458-8-155

Bersamin, M. T., Todd, M., Fisher, D. A., Hill, D. L., Grube, J. W., \& Walker, S. (2008). Parenting practices and adolescent sexual behavior: A longitudinal study. Journal of Marriage and Family, 70, 97-112. doi: 10.1111/j.1741-3737.2007.00464.x

Calafat, A., Juan, M., Becoña, E., \& Mantecón, A. (2008). Qué drogas se prefieren para las relaciones sexuales en contextos recreativos. Adicciones, 20, 37-48.

Calafat, A., Juan, M., Becoña, E., Mantecón, A., \& Ramón, A. (2009). Sexualidad de riesgo y consumo de drogas en el contexto recreativo. Una perspectiva de género. Psicothema, 21, 227-233.

Cohen, J. (1988). Statistical power analysis for the behavioral sciences (2nd edition). Hillsdale, NJ: Erlbaum.

Cooper, M. L. (2002). Alcohol use and risky sexual behavior among college students and youth: Evaluating the evidence. Journal of Studies on Alcohol and Drugs, 14 (Supl.), 101-117.

Cooper, M. L. (2006). Does drinking promote risky sexual behaviour?: A complex answer to a simple question. Current Directions in Psychological Science, 15, 19-23. doi: 10.1111/j.09637214.2006.00385.x

Costa, F. M., Jessor, R., Donovan, J. E., \& Fortenberry, J. D. (1995). Early initiation of sexual intercourse: The influence of psychosocial unconventionality. Journal of Research on Adolescence, 5, 93-121. doi: 10.1207/s15327795jra0501_5

Dogan, S. J., Stockdale, G. D., Widaman, K. F., \& Conger, R. D. (2010). Developmental relations and patterns of change between alcohol use and number of sexual partners from adolescence though adulthood. Developmental Psychology, 44, 1747-1759. doi: 10.1037/ a0019655

Espada, J. P., Huedo-Medina, T. B., Orgilés, M., Secades, R., Ballester, R., \& Remor, E. (2009). Psychometric properties of the HIV/AIDS Knowledge Scale for Spanish adolescents (HIV-KS). Health and Addictions, 9, 149-164.

Espada, J. P., Orgilés, M., Morales, A., Ballester, R., \& Huedo-Medina, T. B. (2012). Effectiveness of a School HIV/AIDS Prevention Program for Spanish Adolescents. AIDS Education \& Prevention, 24, 300-513.

Espada, J. P., Huedo-Medina, T. B., Ballester, R., Remor, E., Secades, R., Orgilés, M., \& Martínez-Lorca, M. (2013). Development of a new instrument to assess AIDS-related attitudes among Spanish Youngsters. Anales de Psicología, 29, 83-89.
European Centre for Disease Prevention and Control/WHO Regional Office for Europe (2011). HIV/AIDS surveillance in Europe 2010. Retrieved at http://ecdc.europa.eu/en/publications/ Publications/111129_SUR_Annual_HIV_Report.pdf

Garcia, A. R., Hernán, M., Cabrera, A., Romo, N., Garcia, J., \& Gutiérrez, J. L. (2006). ¿Tienen los adolescentes y jóvenes que consumen drogas no inyectadas mayor probabilidad de transmisión sexual del VIH? Adicciones, 18, 61-72.

Godin, G., Maticka-Tyndale, E., Adrien, A., Manson-Singer, S., Willms, D., \& Cappon, P. (1996). Cross cultural testing of three social cognitive theories: An application to condom use. Journal of Applied Social Psychology, 26, 1556-1586. doi: 10.1111/j.1559-1816.1996. tb00086.x

Goldstein, A. L., Barnett, N. P., Pedlow, C. T., \& Murphy, J. S. (2007). Drinking in conjunction with sexual experiences among at-risk college student drinkers. Journal of Studies on Alcohol and Drugs, 68, 697-705.

Graves, K. L. (1995). Risky sexual behavior and alcohol use among young adults: results from a national survey. American Journal of Health Promotion, 10, 27-36.

Hull, J. G. \& Bond, C. F. (1986) Social and behavioural consequences of alcohol consumption and expectancy: A meta-analysis. Psychological Bulletin, 99, 347-360. doi: 10.1037/00332909.99.3.347

Leigh, B. C. (1993). Alcohol consumption and sexual activity as reported with a diary technique. Journal of Abnormal Psychology, 102, 490493. doi: 10.1037//0021-843X.102.3.490

Leigh, B. C. \& Stall, R. (1993). Substance use and risky sexual behavior for exposure to HIV: Issues in methodology, interpretation and prevention. American Psychologist, 48, 1035-1045. doi: 10.1037/0003-066X.48.10.1035

Lomba, L., Apóstolo, F., \& Mendes, F. (2009). Consumo de drogas, alcohol y conductas sexuales en los ambientes recreativos nocturnos de Portugal. Adicciones, 21, 309-326.

Moilanen, K. L., Crockett, L. J., Rafaelli, M., \& Jones, B. L. (2010). Trajectories of sexual risk from middle adolescence to early adulthood. Journal of Research on Adolescence, 20, 114-139. doi: 10.1111/j.1532-7795.2009.00628.x

Morrison, D. M., Gilmore, M. R., Hoppe, M. J., Gaylord, J., Leigh, B. C., \& Rainey, D. (2003). Adolescent drinking and sex: Findings from a daily diary study. Perspective of Sexual Reproductive Health, 35, 162-8. doi:10.1111/j.1931-2393.2003.tb00253.x

Patrick, M. E., \& Maggs, J. L. (2009). Does drinking lead to sex? Daily alcohol-sex behaviors and expectancies among college students. Psychology of Addictive Behaviors, 23, 472-481. doi: 10.1037| a0016097

Patrick, M. A., Palen, L. A., Caldwell, L., Gleeson, S., Smith, E., \& Wegner, L. (2010). A qualitative assessment of South African adolescents' motivations for and against substance use and sexual behaviour. Journal of Research on Adolescence, 20, 456-481. doi: 10.1111/j.1532-7795.2010.00649.x

Pingel, E. S., Bauermeister, J. A., Elkington, K. S., Fergus, S., Caldwell, C. H., \& Zimmerman, M. A. (2012). Condom use trajectories in adolescence 
and the transition to adulthood: The role of mother and father support. Journal of Research on Adolescence, 22, 350-366. doi: 10.1111/j.1532-7795.2011.00775.x

Pollock, J. A., Halkitis, P. N., Moeller, R. W., Solomon, T. M., Barton, S. C., Blachman-Forshay, J.,... Love, H. T. (2012). Alcohol use among young men who have sex with men. Substance Use \& Misuse, 47, 12-21. doi: 10.3109/10826084.2011.618963

Rodríguez, A., Hernán, M., Cabrera, A., García, J. M., \& Romo, A. (2007). ¿Qué opinan adolescentes y jóvenes sobre el consumo de drogas recreativas y las conductas sexuales de riesgo? Adicciones, 19, 153168.

Santelli, J. S., Robin, L., Brener, N. D., \& Lowry, R. (2001). Timing of alcohol and other drug use and sexual risk behaviors among unmarried adolescents and young adults. Family Planning Perspectives, 33, 200-205. doi:10.2307/2673782

Sarkar, N. N. (2008). Barriers to condom use. European Journal of Contraception and Reproductive Health Care, 13, 114-122. doi:10.1080/13625180802011302

Seth, P., Sales, J. M., DiClemente, R. J., Wingood, G. M., Rose, E., \& Patel, S. N. (2011). Longitudinal examination of alcohol use: A predictor of risky sexual behavior and trichomonas vaginalis among AfricanAmerican female adolescents. Sexual Transmitted Disease, 38, 96-101. doi:http://dx.doi.org/10.1097/0L0.0b013e3181f07abe

Sohn, D. (1982). Sex differences in achievement self-attributions: An effect-size analysis. Sex Roles, 8, 345-357. doi: 10.1007/BF00287274

Spanish Department of Health, Social Policy and Equality (2011). National Strategy of Sexual and Reproductive Health. Madrid: Author.

UNICEF (2011). Opportunity in Crisis: Preventing HIV from early adolescence to young adulthood. New York: Author.

Vélez-Blasini, C. J. (2008). Evidence against alcohol as a proximal cause of sexual risk taking among college students. The Journal of Sex Research, 45, 118-128. doi:10.1080/00224490801987408

Weinhardt, L. S. \& Carey, M. P. (2000). Does alcohol lead to sexual risk behaviour? Findings from event-level research. Annual Review of Sex Research, 11, 125-157.

World Health Organization (2005). Alcohol use and sexual risk behaviour: A cross-cultural study in eight countries. Geneva: WHO

Zuckerman, M. (2007). Sensation seeking and risky behavior. Washington DC: American Psychological Association. 